\title{
Teaching ethics to medical students
}

\author{
D J Weatherall University of Oxford
}

While few would deny that some attention must be given to ethical issues as part of a medical student's education it has never been clear how this might be best achieved. And at the present time those who are battling with this problem have a further dilemma. On the one hand, the numbers of ethical issues that face the medical profession are increasing at a frightening rate, ranging as they do from genetic engineering to the provision of increasingly expensive resources in the market-place economy of the National Health Service. On the other, medical schools are being encouraged by the General Medical Council (GMC) to decongest the curriculum and to try to reduce rather than increase the amount of taught material. How are we best to prepare young people for battling with problems ranging from QALYs (Quality Adjusted Life Years), and DALYs (Disability Adjusted Life Years), through the complexities of child abuse, to the rights and wrongs of altering the genetic make-up of future generations?

Whatever we do it is extremely important that medical ethics is not taught as a dry, academic subject that is perceived to be remote from day-today practice. It is a topic for which the lecture theatre (and examination hall) has a very limited role. Somewhere early in the medical course, probably in the pre-clinical years, it may be useful to give students some inkling of the background to the way in which a framework for analysing ethical problems can be established. At least they should have a nodding acquaintance with the concepts of duty- and right-based approaches, the principle of utilitarianism and some related basic concepts. But beyond this the only way to make ethics into a 'living' subject is to teach it as a 'real life', case-based discipline.

If the important ethical issues of our times are best aired and taught in the context of individual cases and specialties, how can such an interactive programme be organised? Ideally such discussions should stem directly from the problems of patients or from clinical situations that have been encountered by students along the way during their clinical training. Questions of confidentiality, maintenance of patients on life-support machines, the use of scarce resources, and other difficult issues of this kind, are much better taught in small groups within individual clinical departments or practices and based on actual cases. This approach can be augmented by the organisation of seminars at which students can discuss individual problems that have arisen during their training, and where they can voice some of their fears and uncertainties and meet experts from the many disciplines that encroach on this complex field.

Teaching ethics in this way, or, better still, encouraging a state of mind that will ensure that ethical issues become an integral part of clinical practice throughout a doctor's career, requires considerable organisational skills and enthusiasm. The programme has to be the responsibility of one person or department within a medical school. A directorship of ethical studies, or whatever such a role is labelled, need not be a full-time appointment, but it should involve the overall responsibility for seeing that some form of teaching in ethical issues is integrated into both the pre-clinical and clinical courses.

But the most difficult issue is how what appears to be a rather diverse and unstructured programme of this kind can be organised and monitored in the setting of the overcrowded curriculum that is still the norm in most medical schools. This requires a continuing dialogue between the director of ethical studies and individual academic department heads, consultants and general practitioners. It will never be easy to encourage a series of discussions on ethical issues for a busy surgical firm, yet somehow this is what has to be achieved. If this subject is not spread among the specialties, and into the community, it will inevitably appear to the students as something apart from the reality of day-to-day clinical practice.

It was questions of this kind that stimulated the now highly successful Oxford Practice Skills Project, initiated by Drs Tony Hope and Bill Fulford a few years ago. This programme has provided a central focus point in the Oxford Clinical School at which ethics, communication skills and legal matters that relate to medicine can be both taught and researched. It has the added advantage that it elicits the help of educationalists, philosophers and theologians who have something to offer medical 
students in their training. One of its most valuable roles has been to provide tuition for twenty or more 'tutors' in different specialties, who learn the basics of medical ethics and communication skills and who are then able to teach these topics in the setting of their particular clinical practices. Over half these tutors are general practitioners and so it has been possible to spread the teaching of ethics and communication skills between the hospital and the community. This concept has worked extremely well and has helped to solve a number of the problems of setting medical ethics in an appropriate clinical environment, hence ensuring that it is seen as a relevant part of medical students' education.

It may be important to start as early as possible. After all, students who have been introduced to the ethical issues of animal research, genetic engineering and the health consequences of social injustice in theirm pre-clinical years are much more likely to take easily $\overrightarrow{\bar{\nabla}}$. to the even more complex issues that they are likely to.? encounter in their years on the wards. This will, of $\overrightarrow{\vec{m}}$ course, be easier for medical schools in which the pre-clinical and clinical teaching is becoming more등 integrated along the lines encouraged by the GMC.

Medical ethics, however it is taught, should not be $\overrightarrow{\widetilde{\Phi}}$ a discipline all on its own but, rather, it should 0 become a way of thinking that is as much a part of a student and doctor's way of life as history-taking and $\overrightarrow{0}$ clinical diagnosis. This will only be achieved if it is $\overrightarrow{-}$ fully integrated into all the pre-clinical and clinicale specialties.

D $\mathcal{F}$ Weatherall, FRS, is Regius Professor of Medicine at $\stackrel{\text { N }}{\omega}$ Oxford University. 